\title{
O Uso da Teoria do Programa para a Construção de um Modelo Lógico Aplicado aos Sis- temas Municipais de Cultura no Brasil
}

\section{Using Program Theory to Build a Logical Model Applied to Municipal Culture Systems in Brazil}

\author{
José Ricardo Vitória \\ Universidade Federal de Viçosa - UFV - Brasil \\ josericardovitoria@yahoo.com \\ ORCID: https://orcid.org/0000-0002-0184-3072 \\ Mateus Cerqueira Anício Morais \\ Universidade Federal de Viçosa - UFV - Brasil \\ mateusaniciomorais@gmail.com \\ ORCID: https://orcid.org/0000-0003-4265-3299 \\ Magnus Luiz Emmendoerfer \\ Universidade Federal de Viçosa - UFV - Brasil \\ magnus@ufv.br \\ ORCID: https://orcid.org/0000-0002-4264-8644 \\ Nina Rosa da Silveira Cunha \\ Universidade Federal de Viçosa - UFV - Brasil \\ ninarosa@ufv.br \\ ORCID: https://orcid.org/0000-0002-2292-2159
}

Submetido em 17/12/2019; Aprovado em 30/06/2020.

\begin{abstract}
Resumo
Objetivo: O Sistema Nacional de Cultura (SNC) foi criado com intuito de superar os modelos tradicionais da gestão das políticas culturais no Brasil. Tal sistema pretende integrar a sociedade civil e os três níveis da federação (União, Estados e Municípios) a fim de partilhar responsabilidades comuns, funcionando de forma não concorrencial. Para facilitar o entendimento dos atores responsáveis pela adesão do SNC em seus respectivos municípios, bem como auxiliá-los na criação de seus Sistemas Municipais de Cultura, este trabalho tem por objetivo propor um Modelo Lógico (ML) que seja aplicado no processo de adesão e introdução dos Sistemas Municipais de Cultura no contexto brasileiro. Metodologia: Análise documental. Principais resultados: Foram estabelecidas relações causais entre insumos, atividades e resultados - de curto, médio e longo prazo - e, por fim, delineou-se a Teoria do Programa em nível municipal. Contribuição prática: Após as análises realizadas, materializou-se o ML como tecnologia para a gestão pública no setor cultural.
\end{abstract}

Palavras-Chave: Teoria do Programa; Modelo Lógico; Políticas Públicas; Cultura; Governo Local.

\section{Abstract}

Objective: The National Culture System (NCS) was created with the objective of overcoming the traditional models of cultural policy management in Brazil. Such a system aims to integrate civil society and the three levels of the federation (Union, States and Municipalities) in order to share common responsibilities based on non-competitive functions and to facilitate the understanding of the participants responsible for joining the NCS in their respective municipalities, as well as assist them on the creation of their Municipal Culture Systems. We propose a Logical Model (LM) that is applied to the adhesion process and introduction of Municipal Culture Systems in the Brazilian context. Methodology: Documentary analysis. Main results: From the documents analysis was, causal relationships among inputs, activities and short-, medium- and long-term results were established and, finally, the Program Theory at the municipal level was outlined. Practical Contribution: After the analysis carried out, it was materialized in the Logical Model (LM) as technology for public management in the cultural sector. Keywords: Program Theory; Logical Model; Public Policy; Culture; Local government. 


\section{Introdução}

O histórico do setor da cultura na administração pública revela que ele tem sido conduzido por políticas e ações pontuais. A falta de planejamento, a ausência de políticas para médio e longo prazos, e a descontinuidade das poucas ações, somadas ao caráter imediatista e eventual, utilizadas apenas para ganhos políticos, são usualmente as balizas da gestão cultural no Brasil. Isso fez com que esse setor fosse visto e tratado como uma subárea, sendo um dos menos agraciados com os recursos do orçamento público (Coelho, 1997; Martins, Vitória, Emmendoerfer \& Fioravante, 2017; Peixe, 2013; Rubim, 2006; Vitória, Martins, Emmendoerfer \& Fioravante, 2015).

No intuito de romper com essa conjuntura, por meio de uma nova visão de gestão cultural, surgiu em 2012 o Sistema Nacional de Cultura (SNC), que pode ser considerado um marco histórico da democracia brasileira para o setor cultural (Vitória \& Emmendoerfer, 2015). 0 SNC parte de um conceito sistêmico, segundo o qual se deve integrar a sociedade civil e os três níveis da federação para romper com as antigas formas tradicionais da gestão cultural no Brasil. A partir de práticas democráticas, participativas, descentralizadas e colaborativas entre a sociedade e o poder público busca-se, com o novo arranjo, trabalhar a cultura de forma mais ampla dentro das dimensões econômica, social e humana, como um novo pilar do desenvolvimento (Peixe, 2013).

Para partilhar as responsabilidades comuns é esperado que os sistemas estaduais estejam integrados ao sistema nacional, assim como os municipais estejam integrados aos outros dois, funcionando de forma que não sejam feridos os princípios constitucionais que caracterizam uma federação (Cunha Filho, 2010). Assim, a organização do SNC, da mesma forma que os demais sistemas nacionais já constituídos, como, por exemplo, o Sistema Único de Saúde (SUS), adota a estrutura federativa, formada por sistemas correspondentes nos três níveis de governo. A estrutura básica se reproduz em cada nível, com os devidos ajustes às particularidades locais (Peixe, 2013).

A primeira meta do Plano Nacional de Cultura (PNC) - documento orientador do SNC - é que se tenha até 2020 o "Sistema Nacional de Cultura institucionalizado e implementado, com 100\% das Unidades da Federação (UF) e 60\% dos municípios com sistemas de cultura institucionalizados e implementados" (http://pnc.cultura.gov.br/category/metas/1/, recuperado em 25 de junho de 2020). Com o objetivo de facilitar e acelerar o processo de adesão por parte dos municípios, o antigo Ministério da Cultura (MinC), que, a partir de 2019, passou a ser Secretaria Especial de Cultura no Ministério de Turismo, disponibilizou cartilhas explicativas, palestras, cursos e até um modelo de lei para criação dos sistemas municipais de cultura. Contudo, esse processo tem revelado obstáculos e dificuldades.

Mesmo todos os governos estaduais no Brasil tendo aderido ao Sistema Nacional de Cultura, os desafios se concentram no âmbito municipal, já que, até o final de 2018, apenas 649 municípios brasileiros, dos 5.570 existentes, aderiram ao SNC com sistemas municipais de cultura (http://pnc.cultura.gov.br/category/metas/1/, recuperado em 25 de junho de 2020).

0 principal argumento neste trabalho é que os obstáculos podem estar relacionados com a limitada competência técnica de gestores e demais atores responsáveis pelas políticas culturais nos municípios brasileiros. Alguns autores já apontaram que a falta ou a limitada competência técnica no setor público é um fato recorrente e histórico, tanto no setor da cultura quanto nos demais (Gonçalves \& Simões, 2016; Souza, 2002; Vitória \& Emmendoerfer, 2015; Vitória et al., 2015). Para além da escassez de pessoal qualificado no âmbito municipal, Musa, Passador e Paschoalotto (2017 p. 369) adicionam à lista de dificuldades encontradas para a implantação dos SMCs "a falta de interesse político, a ineficiência na gestão dos recursos destinados à cultura, o não entendimento do processo de implantação, ou seja, trâmites e falta de conhecimento dos níveis, seus significados e suas funcionalidades".

Assim, os obstáculos e dificuldades observados no âmbito do SNC em nível municipal configuram o problema que a área de cultura nas organizações públicas como Prefeitura, Câmara de Vereadores e Conselho Municipal de Cultura enfrenta no cotidiano brasileiro. Frente a esse problema, principalmente no que concerne ao processo de implantação, busca-se promover o seu entendimento aos responsáveis pela adesão em seus respectivos municípios ao SNC de cultura, bem como auxiliá-los na criação dos seus Sistemas Municipais de Cultura (SMC). Neste sentido, este trabalho tem por objetivo propor um Modelo Lógico aplicado ao contexto dos Sistemas Municipais de Cultura no Brasil.

0 fortalecimento de políticas públicas municipais ganha destaque pela sua importância no desenvolvimento das localidades e pela possibilidade de redefinir os papéis dos governos, ao reduzir a distância entre formuladores, implementadores e público-alvo (Faguet, 2014; Weingast, 2014). Além disso, atores locais tendem a expressar melhor as aspirações e necessidades da população e a propiciar maior 
clareza e coerência na definição e coordenação das políticas públicas (Weingast, 2014).

Como já foi apontado em Vitória et al. (2015), a cultura no Brasil está condicionada à importância que cada governo tem dado ao setor. Após o impeachment da presidente Dilma Rousseff, ocorrido em 2016, inicia-se, na gestão de Michel Temer, um processo de descontinuidade atrelado ao desmonte estrutural da institucionalização da política pública de cultura. Esse período é marcado por sérios retrocessos no campo cultural brasileiro (Coimbra \& de Morais, 2019). Após a eleição de Jair Bolsonaro, a cultura passou a ter um caráter secundário e menos valorizado entre as políticas do governo federal. Essa afirmação é sustentada tanto pelas prioridades, inclusive orçamentárias, observáveis em seu plano de gestão governamental, quanto pela extinção do MinC, transformado em uma secretaria que vem sendo marcada pela instabilidade, pela falta de políticas e diretrizes e pela constante troca de secretários responsáveis pela pasta. Somam-se a isso, “[...] os ataques retóricos aos artistas, as dificuldades em relação à mobilização política, a desconstrução efetiva da participação social e dos conselhos nacionais e, repetindo-se historicamente, contudo, de forma mais intensa, as dúvidas em relação ao financiamento [...]" (Silva \& Ziviani, 2020).

Diante desse contexto, o fortalecimento de instituições de valorização da cultura nos entes federativos subnacionais se torna ainda mais necessário. Políticas, como o SMC, tendem a reforçar a importância da cultura para o desenvolvimento das localidades, assim como de todo o país.

É preciso deixar claro que aqui não se objetiva criar um modelo para estruturar as políticas públicas de cultura dos municípios, mas sim facilitar o processo de inserção dos municípios no SNC e a criação dos seus respectivos SMCs, a fim de garantir os benefícios de desenvolvimento das localidades. Depois de formado e devidamente funcionando, as metas e diretrizes definidas no Plano Municipal de Cultura irão orientar, então, as políticas culturais dos municípios "filiados", que deverão adaptá-las à realidade de sua localidade.

A construção de um modelo lógico se justifica por ser um instrumento de fácil entendimento que poderá ser aplicado a todos os municípios brasileiros que desejam criar o seu sistema de cultura, auxiliando-os nos processos de planejamento, monitoramento e avaliação. Apesar de ser preciso fazer algumas adaptações e variações ao longo da implementação, a estrutura básica sugerida neste trabalho poderá ser replicada em todos os municípios.

Após esta introdução que buscou situar o problema, é apresentada uma contextualização sobre o Sistema Nacional de Cultura no Brasil. Em seguida, tem-se o referencial que serviu como guia orientador deste trabalho, no qual foram abordados os temas de teoria do programa e de construção de modelos lógicos. A terceira seção descreve a abordagem metodológica pautada na análise documental que, somada ao referencial teórico, direcionou a proposta de intervenção. Isso culminou na quarta seção, que discorre sobre a construção do Modelo Lógico proposto a partir da teoria do programa para utilização na gestão pública municipal no setor cultural. Por fim, são tecidas as conclusões e considerações acerca da contribuição tecnológica apresentada.

\section{Sistema Municipal de Cultura no Brasil}

Os sistemas públicos buscam garantir meios adequados para que os cidadãos tenham seus direitos constitucionais atendidos, os quais, por meios próprios, não teriam condições de provê-los. Desta forma, a Emenda Constitucional n. 71, de 29 de novembro de 2012, criou o Sistema Nacional de Cultura (SNC) com o intuito de ser um instrumento de gestão compartilhada entre os entes federados e a sociedade civil, para a elaboração e execução de políticas públicas de cultura.

Art. 216-A o Sistema Nacional de Cultura, organizado em regime de colaboração, de forma descentralizada e participativa, institui um processo de gestão e promoção conjunta de políticas públicas de cultura, democráticas e permanentes, pactuadas entre os entes da federação e a sociedade, tendo por objetivo promover o desenvolvimento humano, social e econômico, com pleno exercício dos direitos culturais (Emenda Constitucional n. 71, 2012).

Tendo iniciado as discussões sobre o sistema em 2003, os stakeholders da cultura tiveram importantes conquistas para o setor, passando a compreender o campo da cultura sob três dimensões distintas, porém complementares: a simbólica, a cidadã e a econômica. O SNC é integrado pelos sistemas municipais, estaduais e distrital de cultura, como representados na Figura 1. Esse modelo no Brasil tem como proposta romper com as antigas práticas que conduziam a gestão cultural brasileira, "tais como o isolamento e a prática concorrencial entre os entes federados, o autoritarismo na forma de gestão e na formulação das políticas públicas, a centralização das decisões e dos recursos" (Peixe, 2013, p.8). 


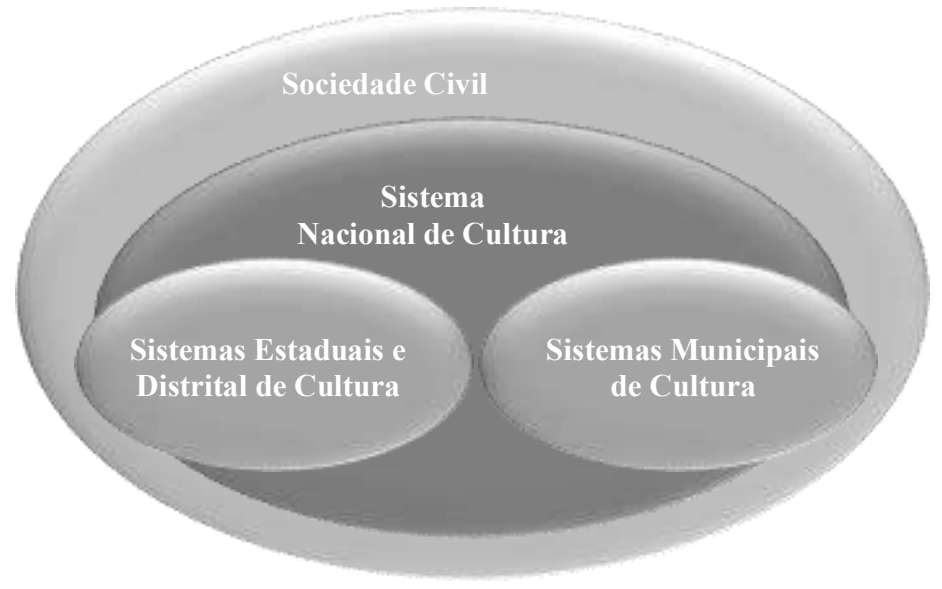

Figura 1 - Sistema Nacional de Cultura

Fonte: Adaptado da Emenda Constitucional n.48 (2005) e de Vitória (2015, p.41).

Neste sentido, a fim de cumprir seus objetivos, o sistema deve compreender em sua estrutura uma série de órgãos e instituições que se comunicam entre si com os demais entes da federação e a sociedade civil. Alguns componentes são opcionais e outros são obrigatórios em cada nível (federal, estadual e municipal) para que o ente federado faça parte do SNC. Sua estrutura está definida no parágrafo segundo da Emenda Constitucional n.71/2012:

$\S 2$ o Constitui a estrutura do Sistema Nacional de Cultura, nas respectivas esferas da Federação: I - órgãos gestores da cultura; II - conselhos de política cultural; III - conferências de cultura; IV - comissões intergestoras; V planos de cultura; VI - sistemas de financiamento à cultura; VII - sistemas de informações e indicadores culturais; VIII - programas de formação na área da cultura; e IX - sistemas setoriais de cultura (Emenda Constitucional n. $71,2012)$.

Como estrutura básica exigida pelo antigo Ministério da Cultura (MinC), para o estabelecimento de um Sistema Municipal de Cultura que seja integrado ao SNC, é necessário que ele seja composto por oito componentes. Todavia, desses componentes possíveis, apenas cinco são obrigatórios no âmbito municipal, como pode ser observado a seguir:

I - coordenação: a) Secretaria Municipal de Cultura ou órgão equivalente. II - instâncias de articulação, pactuação e deliberação: a) Conselho Municipal de Política Cultural; e b) Conferência Municipal de Cultura. III - instrumentos de gestão: a) Plano Municipal de Cultura; e b) Sistema Municipal de Financiamento à Cultura (Peixe, 2013, p.22).

Não obstante, os sistemas ainda têm a opção de implantar mais três componentes - Sistemas de Informações e Indicadores Culturais (SMIIC); Programas de Formação na Área da Cultura; e Sistemas Setoriais de Cultura - tanto nos estados quanto nos municípios (Peixe, 2013). Apesar de não serem obrigatórios, é desejável que os estados e municípios instalem todos os componentes dos sistemas quando possível, "porque são úteis à boa e democrática gestão pública da cultura" (Cunha Filho, 2010, p.85).

A criação de um Sistema Municipal de Cultura (SMC), foco deste trabalho, além de integrar o município ao SNC, visa fortalecer as políticas culturais no município com a participação da sociedade. Depois de estruturado, espera-se que o sistema seja responsável, dentre outras coisas, por contemplar os variados segmentos culturais do município, organizando, gerindo e providenciando recursos financeiros e humanos.

Por meio do acordo de cooperação federativa regulamentado na Lei 12.343 de 2010, foi instituído o documento orientador do SNC, o Plano Nacional de Cultura (PNC), desenvolvido com a finalidade de fazer o planejamento e a implementação de políticas públicas de longo prazo, voltadas à proteção e à promoção da diversidade cultural brasileira (Brasil, 2012). De acordo com o texto legal que o rege, foram estabelecidas 53 metas a serem atingidas pelos entes federativos até 2020. A primeira dessas metas é: "Sistema Nacional de Cultura institucionalizado e implementado, com 100\% das Unidades da Federação (UF) e 60\% dos municípios com sistemas de cultura institucionalizados e implementados" (Portaria MinC n.123, 2011). 
De acordo com as informações disponíveis no portal eletrônico do PNC (http://pnc.cultura.gov.br/category/metas/1/, recuperado em 25 de junho de 2020), todos os estados já aderiram ao Sistema Nacional, sendo o estado do Pará o último assinar o acordo de cooperação no ano de 2019. Dos 5.570 municípios brasileiros, até o final de 2018, 2.644 municípios (47,46 \%) já haviam assinado o acordo de cooperação federativa, porém apenas 512 (9,19\%) aderiram ao SNC com sistemas municipais criados por leis próprias, e apenas 128 (2,29\%) institucionalizaram o SMC por meio de leis do sistema, plano, conselho e fundo de cultura. A Tabela 1 oferece uma síntese do cumprimento da primeira meta do PNC.

Tabela 1 - Situação da Meta 1 (Referente ao Monitoramento 2018-2019)

\begin{tabular}{|c|c|c|c|c|c|c|c|c|c|c|c|}
\hline Indicadores & $\begin{array}{c}\text { Até } \\
2010\end{array}$ & 2011 & 2012 & 2013 & 2014 & 2015 & 2016 & 2017 & 2018 & 2019 & $\begin{array}{c}\text { Ponto } \\
\text { da meta } \\
2020\end{array}$ \\
\hline $\begin{array}{l}\text { Número de esta- } \\
\text { dos e DF com } \\
\text { Acordo de Coo- } \\
\text { peração Federa- } \\
\text { tiva }\end{array}$ & $\begin{array}{c}3,7 \% \\
(1)\end{array}$ & $\begin{array}{c}63,0 \% \\
(17)\end{array}$ & $\begin{array}{c}85,2 \% \\
(23)\end{array}$ & $\begin{array}{c}96,3 \% \\
(26)\end{array}$ & $\begin{array}{c}96,3 \% \\
(26)\end{array}$ & $\begin{array}{c}96,3 \% \\
(26)\end{array}$ & $\begin{array}{c}96,3 \% \\
(26)\end{array}$ & $\begin{array}{c}96,3 \% \\
(26)\end{array}$ & $\begin{array}{c}96,3 \% \\
(26)\end{array}$ & $\begin{array}{c}100 \\
\% \\
(27)\end{array}$ & $\begin{array}{l}100 \% \\
(27)\end{array}$ \\
\hline $\begin{array}{l}\text { Número de esta- } \\
\text { dos e DF com leis } \\
\text { que criaram o } \\
\text { Sistema Esta- } \\
\text { dual/Distrital de } \\
\text { Cultura }\end{array}$ & $\begin{array}{l}7,4 \% \\
(2)\end{array}$ & $\begin{array}{c}11,1 \% \\
(3)\end{array}$ & $\begin{array}{c}14,8 \% \\
(4)\end{array}$ & $\begin{array}{c}18,5 \% \\
(5)\end{array}$ & $\begin{array}{c}25,9 \% \\
(7)\end{array}$ & $\begin{array}{c}33,3 \% \\
(9)\end{array}$ & $\begin{array}{c}40,7 \% \\
(11)\end{array}$ & $\begin{array}{c}55,6 \% \\
(15)\end{array}$ & $\begin{array}{c}63,0 \% \\
(17)\end{array}$ & - & $\begin{array}{c}100 \% \\
(27)\end{array}$ \\
\hline $\begin{array}{l}\text { Número de esta- } \\
\text { dos e DF com leis } \\
\text { que instituciona- } \\
\text { lizaram o Sis- } \\
\text { tema de Cultura } \\
\text { (Leis do sistema, } \\
\text { plano, conselho e } \\
\text { fundo de cultura) }\end{array}$ & & & & & $\begin{array}{l}7,4 \% \\
(2)\end{array}$ & $\begin{array}{c}18,5 \% \\
(5)\end{array}$ & $\begin{array}{l}22,2 \% \\
(6)\end{array}$ & $\begin{array}{c}33,3 \% \\
(9)\end{array}$ & $\begin{array}{c}40,7 \% \\
(11)\end{array}$ & - & \\
\hline $\begin{array}{l}\text { Número de mu- } \\
\text { nicípios com } \\
\text { Acordo de Coo- } \\
\text { peração Federa- } \\
\text { tiva para desen- } \\
\text { volvimento do } \\
\text { Sistema Nacional } \\
\text { de Cultura publi- } \\
\text { cado }\end{array}$ & & & $\begin{array}{c}0,64 \% \\
(36)\end{array}$ & $\begin{array}{l}22,89 \% \\
(1.275)\end{array}$ & $\begin{array}{l}34,47 \% \\
(1.920)\end{array}$ & $\begin{array}{l}39,01 \% \\
(2.173)\end{array}$ & $\begin{array}{l}40,17 \% \\
(2.238)\end{array}$ & $\begin{array}{l}45,74 \% \\
(2.548)\end{array}$ & $\begin{array}{l}47,46 \% \\
(2.644)\end{array}$ & - & $\begin{array}{c}60 \% \\
(3.342)\end{array}$ \\
\hline $\begin{array}{l}\text { Número de mu- } \\
\text { nicípios com leis } \\
\text { que criaram o } \\
\text { Sistema Munici- } \\
\text { pal de Cultura }\end{array}$ & $\begin{array}{c}0,32 \% \\
(18)\end{array}$ & $\begin{array}{c}0,86 \% \\
(48)\end{array}$ & $\begin{array}{c}1,54 \% \\
(86)\end{array}$ & $\begin{array}{c}3,24 \% \\
(181)\end{array}$ & $\begin{array}{l}5,02 \% \\
(280)\end{array}$ & $\begin{array}{l}6,48 \% \\
(361)\end{array}$ & $\begin{array}{c}7,46 \% \\
(416)\end{array}$ & $\begin{array}{c}8,61 \% \\
(480)\end{array}$ & $\begin{array}{l}9,19 \% \\
(512)\end{array}$ & - & $\begin{array}{c}60 \% \\
(3.342)\end{array}$ \\
\hline $\begin{array}{l}\text { Número de mu- } \\
\text { nicípios com leis } \\
\text { que instituciona- } \\
\text { lizaram o Sis- } \\
\text { tema de Cultura } \\
\text { (Leis do sistema, } \\
\text { plano, conselho e } \\
\text { fundo de cultura) }\end{array}$ & & & & $\begin{array}{c}0,41 \% \\
(23)\end{array}$ & $\begin{array}{c}0,65 \% \\
(36)\end{array}$ & $\begin{array}{c}1,04 \% \\
(58)\end{array}$ & $\begin{array}{c}1,72 \% \\
(96)\end{array}$ & $\begin{array}{c}1,97 \% \\
(110)\end{array}$ & $\begin{array}{c}2,29 \% \\
(128)\end{array}$ & - & \\
\hline
\end{tabular}

Fonte: Adaptado do Plano Nacional de Cultura - Meta 1 (http://pnc.cultura.gov.br/category/metas/1/ recuperado em 25 de junho de 2020).

Ressalta-se que a integração entre os esforços provenientes dos estados, municípios e União é desejável pelo seu potencial contributivo para o cumprimento das obrigações perante a cultura em cada unidade federada. A literatura ressalta a importância do ente municipal nesse processo.

A estrutura unitária dos municípios brasileiros, bem como os princípios constitucionais de regência da administração pública (legalidade, impessoalidade, moralidade, publicidade e eficiência) determinam que a organização dos distintos setores que estão sob suas responsabilidades, inclusive a cultura, se materialize de forma sistêmica (Cunha Filho, 2010, p.84).

Nesse sentido, visando colaborar para o avanço da primeira meta do PNC e, consequentemente, para a criação de uma estrutura que seja favorável ao desenvolvimento das políticas culturais dos municípios brasileiros, são apresentados a seguir o referencial teórico e os procedimentos metodológicos que subsidiaram o presente trabalho. 


\section{Teoria do Programa e Modelo Lógico}

A Teoria do Programa se constitui como um conjunto de informações e conhecimentos que permitem o entendimento a respeito de determinado programa. Mais especificamente, trata-se de um instrumento que visa esclarecer como ações, praticadas no processo de implementação de políticas ou projetos, produzem a efetivação de objetivos predeterminados (Weiss, 1999) frente a problemas e causas críticas enunciadas. É também considerado um instrumento estratégico explicativo mais complexo "por lidar com a teoria e os pressupostos subjacentes à intervenção estudada" (Mamede, 2020, p.135). Isso quer dizer que a Teoria do Programa "parte da ideia de que todo programa traz em si uma teoria" (Silva, 1999, p.143). Trata-se das diretrizes formuladas para que os agentes implementadores conduzam suas ações, a fim de atingir suas metas e objetivos.

Em termos empíricos, nem sempre os programas estão descritos de forma clara e objetiva, o que dificulta sua análise no campo teórico (Cassiolato \& Gueresi, 2010). Por vezes, esse fenômeno se apresenta na realidade como um emaranhado de documentos cuja conexão lógica dificilmente é resgatada sem um grande esforço por parte dos agentes interessados. Dessa forma, a análise da Teoria do Programa consiste no resgate do desenho do projeto em questão, de forma que seja gerado um entendimento sistemático dos insumos, atividades, resultados, metas e objetivos esperados no curto, médio e longo prazo (Morra-Imas \& Rist, 2009; Weiss, 1999).

Uma das formas de se desenhar e compreender a Teoria do Programa é por meio da utilização de Modelos Lógicos, ferramentas úteis para a identificação de conexões entre as atividades, produtos e resultados de programas (Sridharan \& Nakaima, 2011, p. 138).

O Modelo Lógico é um recurso metodológico proposto por autores que se dedicam à avaliação de programas (Cassiolato \& Gueresi, 2010). "Basicamente, o Modelo Lógico é uma maneira sistemática e visual de apresentar e compartilhar a compreensão das relações entre os recursos disponíveis para as ações programadas e as mudanças ou resultados que se espera alcançar" (Cassiolato \& Gueresi, 2010, p.6).

Tendo em vista que os programas das políticas, antes de tudo, surgem na mente das pessoas que as idealizam (Pawson \& Tiley, 2004), eles podem ser organizados a partir de uma cadeia lógica do tipo "SE - ENTÃO" estabelecendo uma relação de causalidade das etapas propostas pelo programa (Cassiolato \& Gueresi, 2010; WK Kellogg Foundation, 2004;). Conforme é exemplificado por Cassiolato e Gueresi (2010).

Considerando as percepções sobre os fatores-chave do contexto, SE utilizo tais recursos, ENTÃO implemento tais ações; se tais ações são executadas, ENTÃo obtenho tais produtos para grupos de beneficiários. SE tais produtos são realizados, ENTÃO alcanço os resultados intermediários. SE resultados intermediários ocorrem, ENTÃO obtenho resultado final que irá levar ao alcance do objetivo da intervenção (Cassiolato \& Gueresi, 2010, p.14, grifo nosso).

Levando em consideração que tais processos são hipotéticos, por meio de avaliações é possível verificar como os processos reais de mudança diferem de suas hipóteses (Sridharan \& Nakaima, 2011). Devido ao fato de essa cadeia nem sempre estar explícita, para construção desses processos, é preciso entender qual é o desenho proposto pelo programa ou qual é a Teoria do Programa (Moreira \& Silveira, 2015; Morra-Imas \& Rist, 2009; Pawson \& Tiley, 2004; Sridharan \& Nakaima, 2011; Weiss, 1999; WK KellogFoundation, 2004).

Segundo Cassiolato e Gueresi (2010 p. 9), a construção de um Modelo Lógico deveria ser o primeiro passo ao elaborar um programa, visto que este é "um método para enunciar o problema e elaborar sua explicação". Dessa forma, seria possível entender de antemão qual o problema a ser enfrentado pelo programa, seus objetivos, público-alvo e quais mudanças esperadas e, assim, orientar quais ações serão desenvolvidas pelo programa (Cassiolato \& Gueresi, 2010 p. 9).

O Modelo Lógico pode servir também como instrumento de avaliação prospectiva do programa, ao considerar que ele é um instrumento que facilita o planejamento e a comunicação do funcionamento da Teoria do Programa. Ele deve expor de forma simplificada e organizada "as ações componentes de um programa de forma articulada aos resultados esperados, apresentando também as hipóteses e as ideias que dão sentido à intervenção" (Cassiolato \& Gueresi, 2010, p.4).

Para construção de Modelos Lógicos que objetivam analisar as políticas públicas, uma das lógicas sugeridas é a diferenciação dos indicadores de insumo, processo, resultado e impacto (Jannuzzi, 2005). Tais distinções nem sempre ficam bem esclarecidas a depender da extensão dos objetivos 
(Jannuzzi, 2014). Sujeitam-se também ao foco dado ao programa, podendo surgir diferentes arranjos, mas sempre visando esclarecer quais e em qual sentido serão encaminhados os esforços do programa.

De acordo com Jannuzzi (2014, p.32), os sistemas de monitoramento mais efetivos "partem de modelos lógicos de intervenção que retratam, de fato, o desenho do programa, a partir do qual se torna possível selecionar indicadores-chave com os dados gerados na operação e atividades do próprio programa, em seus sistemas de gestão". E para construção dos Modelos Lógicos é preciso ter bem claros os meios de verificação das metas pretendidas, que serão traduzidas em indicadores (Januzzi, 2014).

A partir do crescente reconhecimento da cultura para o desenvolvimento humano, social, cultural e econômico, a criação e a inserção dos indicadores culturais, tanto quantitativos quanto qualitativos, têm sido discutidas em grande parte do mundo, principalmente em países em que as políticas culturais vêm ganhando destaque (Calabre, 2009; Escande, 2003; Ferres, Adair \& Jones, 2010; Gerbner, 1969; Hong, 2014; Madden, 2005; Ortega-Villa \& Ley-Garcia, 2017; Tabrett, 2014).

Alguns trabalhos destacam as dificuldades de se criar indicadores no nível nacional e destacam a imprescindível necessidade de se criar indicadores culturais locais (Coll-Serrano, Carrasco-Arroyo, Blasco-Blasco \& Vila-Lladosa, 2012; Johanson, Glow \& Kershaw, 2014), considerando que, somente nas localidades, as pluralidades culturais podem ser captadas. A partir dos indicadores locais, quantitativos e qualitativos, pode-se subsidiar a criação de indicadores regionais, estaduais e/ou nacionais.

\section{Procedimentos Metodológicos para a Construção do Modelo Lógico}

Esta pesquisa caracteriza-se de forma predominante como qualitativa. Na perspectiva da policy analysis, os métodos qualitativos "possibilitam a compreensão do funcionamento de projetos e programas, lançando luzes sobre as não linearidades do processo de produção de políticas públicas, bem como sobre as limitações e imperfeições que aparecem e são enfrentadas na execução das ações" (Pires, Lopes \& Silva, 2010, p. 670).

\section{Tabela 2 - Lista de Documentos Analisados}

\section{Documento}

Emenda Constitucional no 48, de 10 de Agosto de 2005

Caderno: Diretrizes Gerais para o Plano Nacional de Cultura

Por que aprovar o Plano Nacional de Cultura - Conceitos, participação e expectativas

0 que é Sistema Municipal de Cultura

\begin{tabular}{|ccc}
\hline Tipo & \multicolumn{1}{c}{ Órgão } & Ano \\
\hline Lei & Governo Federal & 2005 \\
\hline Cartilha & Ministério da Cultura & 2008 \\
\hline Cartilha & Ministério da Cultura & 2009 \\
\hline
\end{tabular}

Cultura, cidade e desenvolvimento local: como estruturar a
política cultural no seu município e acessar os recursos fede-

Cartilha

Fundação Catarinense de Cultura

rais

Lei $\mathrm{n}^{\circ}$ 12.343, de 2 de dezembro de 2010

Cartilha

Ministério da Cultura

2009

Federalismo Cultural e Sistema Nacional de Cultura: contri-

buição ao debate

Estruturação, Institucionalização e Implementação do Sis-

tema Nacional de Cultura

Oficina de Implementação de Sistemas Estaduais e Munici-

pais de Cultura

Cartilha do Sistema Nacional de Cultura para os Municípios

Minuta de projeto de lei que cria o Sistema Municipal de Cul-

tura a ser adaptado para a realidade de cada município.

As políticas públicas e suas narrativas: o estranho caso entre

o Mais Cultura e o Sistema Nacional de Cultura

Lei

Governo Federal

2010

Livro

Edições UFV Fortaleza

2010

Guia de Orientações para os Municípios Sistema Nacional de Cartilha

Cultura Perguntas e Respostas

\begin{tabular}{lcccc}
\hline Emenda Constitucional no 71, de 29 de novembro de 2012 & Lei & Governo Federal & 2012 \\
\hline $\begin{array}{l}\text { Oficina de Implementação de Sistemas Estaduais e Munici- } \\
\text { pais de Cultura }\end{array}$ & Cartilha & Ministério da Cultura & 2013 \\
Como fazer um plano de cultura & Cartilha & Ministério da Cultura & 2013 \\
\hline $\begin{array}{l}\text { Coleção Política e Gestão Culturais - Sistema Nacional de } \\
\text { Cultura }\end{array}$ & Cartilha & Secretaria de Cultura do Governo da & 2013 \\
\hline Memórias e reflexões sobre o Sistema Estadual de Cultura & Livro & Governo do Estado de Minas Gerais & 2014 \\
\hline Portal eletrônico do Sistema Nacional de Cultura (SNC) & Site & Ministério do Turismo & 2020 \\
\hline Portal eletrônico do Plano Nacional de Cultura (PNC) & Site & Ministério do Turismo & 2020 \\
\hline
\end{tabular}

Fonte: Elaboração nossa. 
Além da revisão de literatura, foi utilizada a pesquisa documental para coleta e posterior análise dos dados. Segundo Pires et al. (2010, p. 672), "A coleta e análise sistemática de documentos, dos mais variados tipos, podem ocorrer junto às organizações alvo de avaliação ou em instituições responsáveis por registros oficiais, como arquivos públicos, ou por produções bibliográficas, como bibliotecas". Nesse sentido, a coleta ocorreu por meio do acesso e da leitura de documentos públicos, por meio de pesquisa na internet em sites oficiais ou em quaisquer outros documentos que versassem sobre a criação de Sistemas Municipais de Cultura. Esses documentos foram listados na Tabela 2.

Para análise dos dados, foi contemplada a análise de conteúdo categorial (Bardin, 2016; Mozzato \& Grzybovski, 2011), cujas categorias foram os componentes essenciais dos Sistemas Municipais de Cultura tratados na seção anterior, os quais foram cotejados com as dimensões (insumos, atividades, resultados de curto, médio e longo prazo) que direcionam a teoria do programa. Ressalta-se que a elaboração da teoria do programa é o primeiro passo a ser dado para o entendimento das etapas necessárias para a criação de um sistema municipal de cultura e, posteriormente, para a construção do Modelo Lógico proposto neste trabalho.

\section{Análise e Aplicação do Modelo Lógico a Sistemas Municipais de Cultura}

Buscou-se explicitar aqui cada etapa do processo de adesão e introdução de um SMC, sob o molde sugerido pelo antigo MinC. Cada etapa foi construída a partir da compilação de dados encontrados em cartilhas, leis, e quaisquer outros documentos disponíveis nos sites oficiais dos órgãos responsáveis pelas políticas públicas de cultura no Brasil, que abordassem a criação de SMCs.

A partir da análise desses documentos, puderam-se estabelecer as relações causais (Se - Então) entre insumos, atividades e resultados - de curto, médio e longo prazos - e, por fim, delinear a Teoria do Programa aplicada em nível local. Em resumo, procurou-se identificar e analisar os elementos contextuais e normativos que caracterizam o Programa, que, por fim, materializou o Modelo Lógico Aplicado aos Sistemas Municipais de Cultura no Brasil.

Por inputs (insumos), entendem-se os passos necessários para regularizar e alinhar os municípios aos objetivos do PNC, por meio da adesão ao SNC, sendo eles: Assinatura do Termo de Adesão junto ao Minc; Criação da Legislação do SMC; Convocação da população para a Conferência; e Criação do SMIIC.

Primeiramente, o município precisa aderir ao SNC cadastrando-se no portal (http://snc.cultura.gov.br) e enviar a documentação necessária, como o Termo de Adesão, documento inicial que firma a parceria entre os Governos Municipais e Estaduais com o Governo Federal, permitindo a execução do programa nacional concomitantemente nos três níveis, cada um com suas devidas obrigações. Para assiná-los, a princípio, não é necessário que o município tenha nenhum dos componentes já instituídos, apenas que esclareça quando começou ou começarão os processos para criação do SMC declarados em um plano de trabalho. Todo o cadastro deve ser feito no site oficial do Sistema Nacional de Cultura (http://portalsnc.cultura.gov.br/), onde pode ser encontradas informações sobre como fazer parte do SNC. Após todos os procedimentos, a aprovação é declarada e poderá ser verificada no Diário Oficial da União. Dessa forma:

SE o município firmar adesão ao Sistema Nacional de Cultura, ENTÃO assume-se o compromisso de criar o seu Sistema Municipal.

Posteriormente, deve ser elaborada uma lei própria instituindo o SMC. A lei deve criar conexões entre os componentes que serão previstos para composição do Sistema e devem estar previstas suas estruturas e os principais objetivos. Essa lei deve ser encaminhada à Câmara de Vereadores do município para que possa ser aprovada e dar ao sistema o caráter legal. A lei poderá seguir alguns modelos propostos pelo MinC, contudo, deverão ser feitas as adaptações necessárias para a realidade de cada município. A verificação da lei poderá ser feita junto ao banco de dados da Câmara de Vereadores do município, em muitos casos, disponíveis on-line. Assim:

SE o SMC for regularizado legalmente, ENTÃO o município se compromete a cumprir o que foi previsto na lei.

Feito isso, o prefeito, por meio da secretaria ou órgão gestor responsável pelo setor da cultura, deverá convocar a população interessada para uma Conferência Municipal de Cultura, onde deverão ser 
decididas as diretrizes das políticas culturais do município. O SNC estabelece que as Conferências Nacionais de Cultura sejam realizadas pelo menos a cada quatro anos, sendo antecedidas pelas Conferências Estaduais e Municipais, sugeridas para acontecerem de dois em dois anos, ou quando for necessário e houver justificativas. Na Conferência Municipal serão levantadas as demandas e as prioridades culturais do município, que deverão ser registradas na forma de atas ou anais, sendo detalhadas e traduzidas em programas, projetos e ações que darão suporte posteriormente ao Plano de Cultura do Município (Brasil, 2012). Essa convocação deverá ser noticiada o máximo possível, através dos meios de comunicação oficiais e não oficiais disponíveis no município, para que toda a população interessada possa comparecer. Dado que:

SE a população for devidamente convocada, ENTÃO os interessados poderão se dispor a comparecer na Conferência.

Nesse contexto, é urgente a criação de indicadores culturais, que devem ser construídos a partir de informações de cada localidade. Como forma de monitorar e avaliar o programa, desde o início recomenda-se a criação do Sistema Municipal de Informações e Indicadores Culturais (SMIIC).

Sistema de Informações e Indicadores Culturais é o conjunto de instrumentos de coleta, organização, análise e armazenamento de dados - cadastros, diagnósticos, mapeamentos, censos e amostras - a respeito da realidade cultural sobre a qual se pretende atuar. Por meio do levantamento dos artistas, produtores, grupos de cultura popular, patrimônio material e imaterial, eventos, equipamentos culturais, órgãos públicos e privados e movimentos sociais de cultura é possível planejar e executar com maior precisão programas e projetos culturais. Os indicadores podem ser qualitativos e quantitativos (Brasil, 2012, pp. 28-29).

Apesar de não ser um dos componentes obrigatórios para a criação do SMC, acredita-se que, para um melhor monitoramento e avaliação, seja necessário que todas as unidades da federação tenham um SMIIC, uma vez que a existência de dados sobre cultura do município favorece a análise e o monitoramento das políticas públicas. Mesmo que o município não tenha condições de implantar um SMIIC arrojado, como indicado em Brasil (2012), sugere-se que haja ao menos um sistema de cadastro simplificado dos artistas, produtores e atividades culturais da localidade em planilhas virtuais do tipo "Excel".

Esse sistema poderá ser implantado desde o momento da criação do SMC. A criação de indicadores locais favorece a construção de uma série histórica de dados dos municípios. Dessa forma, o SMIIC se torna um banco de dados a respeito da cultura dos municípios. Os indicadores sinalizarão tendências e permitirão avaliar as políticas ao longo do tempo, a sua evolução ou eventual retrocesso e os insumos para novas ações (Brasil, 2012). Desse modo:

SE houver um SMIIC, ENTÃo é possível gerar dados e informações para a verificação e a criação de indicadores para o setor.

Após a inclusão dos elementos (inputs) essenciais para adesão ao SNC, deverão ser desenvolvidas algumas atividades necessárias para a introdução do Sistema Municipal de Cultura, sendo elas: realização da Conferência Municipal de Cultura; cadastramento da população interessada para votar e/ou se candidatar na eleição do Conselho.

Assim, ainda durante a Conferência, convocada preferencialmente logo após a criação da Lei que institui o SMC pela Câmara de Vereadores, deverão ser definidas as diretrizes para as políticas culturais do município, indicando os setores mais expressivos para a cultura local. Esses setores serão posteriormente representados por membros da sociedade civil, com cadeira cativa, dentro do Conselho Municipal de Política Cultural. 0 indicativo do número de participantes na Conferência poderá ser verificado a partir da lista de presença. Como pressuposto, tem-se que:

SE houver participação das comunidades na Conferência, ENTÃO é possível discutir os anseios culturais da população.

Também deverá dar início ao cadastro dos interessados a votar ou a se candidatar para serem os representantes da sociedade civil no Conselho. Os cadastros poderão iniciar durante a Conferência, mas deverão continuar sendo feitos durante um determinado período para que os demais interessados, que não estiveram presentes, possam se cadastrar. 0 número de votantes e elegíveis cadastrados poderá ser 
verificado no SMIIC que, preferencialmente, já teria sido criado.

SE os interessados se cadastrarem (tanto para votar, quanto para serem eleitos), ENTÃO poderá ocorrer a eleição do Conselho.

Dessa forma, após a eleição, como primeiro resultado, considerado de curto prazo, será criado o Conselho Municipal de Política Cultural (CMPC). Os conselheiros eleitos serão os representantes da sociedade civil nos seus respectivos segmentos artístico-culturais que ocuparão, no mínimo, 50\% das cadeiras do Conselho. Os restantes serão representantes indicados pelos órgãos do poder público local. É recomendado, para ambos, mandatos de dois anos. Espera-se que, para que ocorra uma verdadeira participação social de forma democrática, os CMPCs sejam consultivos e deliberativos. A verificação dos candidatos eleitos para representar o seu correspondente segmento cultural poderá ser feita por meio da ata de conferência dos votos. Espera-se que:

SE o Conselho for criado e estiver funcionando, ENTÃO as políticas de cultura serão conduzidas de forma participativa.

Após criação do Conselho Municipal de Política Cultural, os membros deverão dar início ao processo de elaboração do seu Regimento Interno, bem como indicar a comissão responsável pela coleta de dados e elaboração do Plano Municipal de Cultura, que poderá ser feita com o auxílio do SMIIC.

Plano de Cultura - é um instrumento de gestão de médio e longo prazo, no qual o Poder Público assume a responsabilidade de implantar políticas culturais que ultrapassem os limites de uma única gestão de governo. 0 Plano estabelece estratégias e metas, define prazos e recursos necessários à sua implementação. A partir das diretrizes definidas pela Conferência de Cultura, que deve contar com ampla participação da sociedade, o Plano é elaborado pelo órgão gestor com a colaboração do Conselho de Política Cultural, a quem cabe aprová-lo (Brasil, 2012, pp. 27-28).

SE houver a preparação/aprovação do Plano Municipal de Cultura, ENTÃo o município terá formulado um condutor das suas políticas culturais para os próximos dez anos.

Tendo em vista que o Plano será o principal condutor das políticas culturais do município nos próximos anos (dez anos sugeridos pelo SNC), é importante que seja bem trabalhado, articulado e pensado com base nas necessidades culturais do município. Espera-se ainda que o plano do município esteja alinhado com o do seu respectivo estado e também com o plano nacional, evitando práticas concorrenciais entre os entes federados. Após a aprovação pelo Conselho Municipal de Política Cultural, o plano deverá ser aprovado também pela Câmara Municipal de Vereadores para que tenha caráter legal. Dessa forma, poderá ser apresentado como um documento oficial para a comunidade municipal.

Com a introdução do plano, que é um dos resultados esperados no médio prazo, o próprio servirá de base para sociedade verificar quais são as diretrizes, metas e prioridades para o setor cultural do município. Nele também devem estar claros quais serão os indicadores e instrumentos para o monitoramento e a avaliação do plano nesses anos. Dessa forma:

SE houver a preparação/aprovação do Plano Municipal de Cultura, ENTÃO o município terá formulado um condutor das suas políticas culturais para os próximos dez anos.

Outro resultado de médio prazo esperado é a instituição do Sistema Municipal de Financiamento à Cultura (SMFC), que já deverá estar previsto na lei que regula o SMC.

Sistema de Financiamento à Cultura é o conjunto dos instrumentos de financiamento público da cultura, tanto para as atividades desenvolvidas pelo Estado, como para apoio e incentivo a programas, projetos e ações culturais realizadas pela Sociedade. Pode ser de quatro tipos: Orçamento Público (reembolsável e não-reembolsável), Fundo (reembolsável e não-reembolsável); Incentivo Fiscal; e Investimento (reembolsável) (Brasil, 2012, p. 29).

O SMFC conduzirá todos os recursos financeiros destinados à cultura do município, sejam advindos de recursos próprios, sejam advindos de repasses dos Estados e da União. Em especial, deverá ser criado o Fundo Municipal de Cultura com conta bancária própria, que será, em muitos municípios, o principal meio de financiamento à cultura, pois possibilita o repasse fundo a fundo pelos governos federal e estadual. 
"Os Fundos aplicam recursos, quase sempre de origem orçamentária, diretamente na execução ou no apoio a programas, projetos e ações culturais, realizadas pelo Poder Público e pela Sociedade" (Brasil, 2012, p.29). A aplicação desses recursos deverá ser focalizada em projetos e ações estratégicas que tenham o intuito de suprir as carências e/ou exaltar as potencialidades de cada localidade. Todas as transações de manutenção do SMFC, bem como os editais lançados para distribuição de recursos do fundo municipal de cultura, deverão estar disponíveis no portal de transparência do município para que toda a população interessada tenha acesso. Dessa forma:

SE houver disponibilidade de recursos e esses forem devidamente aplicados, ENTÃo o município terá condições de implementar as políticas formuladas no plano.

Ao fim destas etapas, que podem ocorrer de forma separada ou concomitante, o município terá, como resultado de longo prazo, estruturado de maneira integral o seu Sistema Municipal de Cultura (SMC), que deve criar as conexões entre seus próprios componentes, além de integrá-los ao sistema de seu estado e ao Sistema Nacional de Cultura. Essa estrutura poderá facilitar a condução das políticas culturais do Município.

Todo o procedimento descrito até aqui partiu de processo hipotético global de mudança esperado, onde entende-se que:

SE for criado o Sistema Municipal de Cultura, atrelado aos demais sistemas (federal, estaduais e municipais), ENTÃO o município poderá trabalhar suas políticas culturais de maneira sistêmica e participativa de forma colaborativa com os demais entes federados.

Assim, tem-se a materialização da proposta do Modelo Lógico exposto na Tabela 3. Recomendase a leitura do Modelo Lógico da esquerda para direita, de baixo para cima, entendendo-se que os insumos possibilitam a execução das atividades que, ao serem realizadas, geram os resultados (de curto, médio e longo prazos). Como instrumento de avaliação, a verificação de cada etapa pode se tornar referência para o cumprimento das atividades e o input para a realização da etapa seguinte. Assim, o indicador de sucesso configura-se como somatório das etapas que possibilitaram a criação do SMC. Por seu turno, a criação de SMC ajudaria a monitorar e avaliar políticas públicas de cultura do município, com definição de indicadores comuns, úteis para a gestão/governança pública multinível.

Nesta direção, destaca-se, dentre as etapas, a importância da criação do Sistema Municipal de Indicadores e Informações Culturais para o acompanhamento da política pública. Esse instrumento permite entender, ao longo do tempo, os avanços do sistema de cultura do município, bem como os atores e entidades que estiveram empenhados para o seu bom desempenho. Isso auxiliaria a garantir meios de verificação dos números das atividades culturais de forma geral em nível municipal, podendo gerar indicadores, desde o registro de envolvidos com a gestão cultural, as artes, as tradições, até o impacto financeiro do SMC sobre orçamento municipal voltado para a cultura. Além disso, as Tabelas 1 e 3, respectivamente, por meio dos indicadores e componentes apresentados, podem inspirar a geração de indicadores genéricos, embora preliminares, para o acompanhamento da criação de um SMC.

Tabela 3 - Modelo Lógico aplicado à implantação de Sistemas Municipais de Cultura no Brasil

\begin{tabular}{|c|c|c|c|}
\hline Dimensões & Componentes & Meios de verificação & Suposições \\
\hline $\begin{array}{l}\text { Resultados } \\
\text { de Longo } \\
\text { Prazo }\end{array}$ & $\begin{array}{l}\text { Institucionalização } \\
\text { do Sistema Munici- } \\
\text { pal de Cultura }\end{array}$ & $\begin{array}{l}\text { Verificar o funcionamento dos de- } \\
\text { mais componentes especificados, } \\
\text { inclusive com monitoramento } \\
\text { eletrônico com dados de domínio } \\
\text { público, semelhante aos portais } \\
\text { do SNC e PNC. }\end{array}$ & $\begin{array}{l}\text { SE for institucionalizado o Sistema Municipal de } \\
\text { Cultura, atrelado aos demais sistemas (federal, } \\
\text { estaduais e municipais), ENTÃO o município po- } \\
\text { derá trabalhar suas políticas culturais de maneira } \\
\text { sistêmica e participativa de forma colaborativa } \\
\text { com os demais entes federados. }\end{array}$ \\
\hline \multirow{2}{*}{$\begin{array}{l}\text { Resultados } \\
\text { de Médio } \\
\text { Prazo }\end{array}$} & $\begin{array}{l}\text { Criação do Sistema } \\
\text { Municipal de Fi- } \\
\text { nanciamento à Cul- } \\
\text { tura }\end{array}$ & $\begin{array}{l}\text { Portal de transparência do muni- } \\
\text { cípio. }\end{array}$ & $\begin{array}{l}\text { SE houver a disponibilidade de recursos e esses } \\
\text { forem bem aplicados, ENTÃ o o município terá } \\
\text { condições de implementar as políticas formula- } \\
\text { das no plano. }\end{array}$ \\
\hline & $\begin{array}{l}\text { Lançamento do } \\
\text { Plano Municipal de } \\
\text { Cultura }\end{array}$ & $\begin{array}{l}\text { O próprio documento que ilustra } \\
\text { o plano. Atas do CMPC e da Câ- } \\
\text { mara Municipal dos Vereadores }\end{array}$ & $\begin{array}{l}\text { Se houver a preparação/aprovação do Plano Mu- } \\
\text { nicipal de Cultura, ENTÃO o município terá for- } \\
\text { mulado um condutor das políticas culturais para } \\
\text { os próximos dez anos. }\end{array}$ \\
\hline
\end{tabular}




\begin{tabular}{|c|c|c|c|}
\hline $\begin{array}{l}\text { Resultados } \\
\text { de Curto } \\
\text { Prazo }\end{array}$ & $\begin{array}{l}\text { Criação do Conse- } \\
\text { lho Municipal de } \\
\text { Políticas Culturais } \\
\text { (CMPC) }\end{array}$ & $\begin{array}{l}\text { Membros eleitos/ Ata de confe- } \\
\text { rência dos votos. Elaboração de } \\
\text { Regimento Interno. }\end{array}$ & $\begin{array}{l}\text { SE o Conselho for criado e estiver funcionando, } \\
\text { ENTÃO as políticas de cultura serão conduzidas } \\
\text { de forma participativa. }\end{array}$ \\
\hline \multirow[t]{2}{*}{ Atividades } & $\begin{array}{l}\text { Cadastramento da } \\
\text { população interes- } \\
\text { sada para votar e } \\
\text { se candidatar na } \\
\text { eleição do Conse- } \\
\text { lho }\end{array}$ & $\begin{array}{l}\text { O número de votantes e elegíveis } \\
\text { cadastrados poderá ser verificado } \\
\text { no SMIIC. }\end{array}$ & $\begin{array}{l}\text { SE os interessados se cadastrarem (tanto para } \\
\text { votar quanto para serem eleitos), ENTÃO poderá } \\
\text { ocorrer a eleição do Conselho. }\end{array}$ \\
\hline & $\begin{array}{l}\text { Realização da Con- } \\
\text { ferência Municipal } \\
\text { de Cultura }\end{array}$ & $\begin{array}{l}\text { Número de participantes a partir } \\
\text { da lista de presença. }\end{array}$ & $\begin{array}{l}\text { SE houver participação das comunidades na Con- } \\
\text { ferência, ENTÃO é possível discutir os anseios } \\
\text { culturais da população. }\end{array}$ \\
\hline \multirow{4}{*}{ Insumos } & $\begin{array}{l}\text { Criação do Sistema } \\
\text { Municipal de Indi- } \\
\text { cadores e Informa- } \\
\text { ções Culturais } \\
\text { (SMIIC). }\end{array}$ & $\begin{array}{l}\text { Número e qualidade das informa- } \\
\text { ções inseridas no próprio SMIIC. }\end{array}$ & $\begin{array}{l}\text { SE houver um SMIIC, ENTÃO é possível gerar da- } \\
\text { dos e informações permitindo a verificação e a } \\
\text { criação de indicadores para o setor. }\end{array}$ \\
\hline & $\begin{array}{l}\text { Convocação da po- } \\
\text { pulação para a } \\
\text { Conferência }\end{array}$ & $\begin{array}{l}\text { Quantidade de meios de comuni- } \\
\text { cação oficiais e não oficiais dispo- } \\
\text { níveis no município. } \\
\text { Frequência das comunicações nos } \\
\text { respectivos meios definidos. }\end{array}$ & $\begin{array}{l}\text { SE a população for devidamente convocada, EN- } \\
\text { TÃO os interessados poderão se dispor a compa- } \\
\text { recer na Conferência. }\end{array}$ \\
\hline & $\begin{array}{l}\text { Criação da Legisla- } \\
\text { ção do SMC }\end{array}$ & $\begin{array}{l}\text { Banco de dados das leis do muni- } \\
\text { cípio (on-line) }\end{array}$ & $\begin{array}{l}\text { SE for regularizado legalmente, ENTÃO o muni- } \\
\text { cípio se compromete a cumprir o que foi pre- } \\
\text { visto na lei. }\end{array}$ \\
\hline & $\begin{array}{l}\text { Assinatura do } \\
\text { Termo de Adesão } \\
\text { junto ao MinC }\end{array}$ & $\begin{array}{l}\text { Publicação no Diário Oficial da } \\
\text { União. }\end{array}$ & $\begin{array}{l}\text { SE o município firmar adesão ao Sistema Nacio- } \\
\text { nal de Cultura, ENTÃO se assume o compro- } \\
\text { misso de criar o seu Sistema Municipal. }\end{array}$ \\
\hline
\end{tabular}

Fonte: Elaborado nossa.

Portanto, a criação do SMC será computada como índice nacional, ao somar mais um município com sistema de cultura institucionalizado e implementado, como almejado pela primeira meta do PNC. A relevância do cumprimento desta meta se dá principalmente em relação às outras 52 metas estabelecidas, uma vez que dependem direta ou indiretamente do cumprimento desta primeira. Então, todo o esforço que contribua no sentido de sua concretização colabora também com a efetivação do SNC de forma geral.

\section{Conclusão e contribuições}

Ao observar os processos desenvolvidos com base no desenho do programa, disperso em vários documentos, foi possível sugerir a Teoria do Programa aqui exposta com a finalidade de sintetizá-la de forma integrada para área cultural em nível municipal. Entende-se que, se os insumos forem devidamente aplicados e as atividades realizadas de forma adequada, então será possível obter os resultados - de curto, médio e longo prazos - esperados. A cadeia de causalidade desenvolvida, trazendo de forma explícita a Teoria do Programa, possibilita a visualização do desenho hipotético da mudança esperada por essa intervenção, a fim de minimizar problemas, inclusive como aqueles apresentados na seção introdutória deste trabalho.

É preciso lembrar que este trabalho não pretendeu fornecer subsídios para a formulação de políticas culturais dos municípios e sim propor um instrumento que facilite o processo de adesão dos municípios ao SNC e/ou a introdução de um Sistema Municipal de Cultura em cada localidade. A partir da criação deste sistema, o município terá condições de formular suas políticas de cultura com a participação da população local, decidindo onde os recursos serão aplicados, quais caminhos serão seguidos e quais indicadores a serem monitorados pelo município. Isso considerando que cada localidade deve pensar suas políticas de acordo com sua realidade - contextual, cultural e de recursos -, buscando fazêlas de maneira colaborativa e sem potencializar rivalidades com outros municípios e os demais entes da federação.

Além disso, o Modelo Lógico se limita ao cumprimento de uma meta e, mesmo assim, a depender da realidade do município, ainda terá que realizar outros passos como, por exemplo, a criação do próprio 
órgão gestor, se não existir. 0 Modelo Lógico proposto enquanto contribuição tecnológica para a gestão pública no setor cultural visa criar uma linha de raciocínio que facilite a execução das tarefas, mas não é, e nem pretende ser, a única forma de execução a fim de solucionar o problema. Não obstante o fator limitador, espera-se que a criação de um Modelo Lógico para a implementação do Sistema Nacional de Cultura no âmbito municipal inspire futuros esforços para capacitações e validação empírica do instrumento apresentado neste trabalho, bem como estudos em perspectiva comparada entre municípios.

Contudo, mesmo que haja alterações no SNC com as mudanças de governos, infere-se que a necessidade de gestão e governança pública do setor cultural nos níveis nacional, estadual e principalmente municipal tende a ser perene, inclusive para nortear o planejamento do setor nas próximas décadas e em articulação com os Objetivos de Desenvolvimento Sustentável (ODS) da Agenda Global da Organização das Nações Unidas (ONU). Logo, a proposição do Modelo Lógico apresentado pode auxiliar no enfrentamento do problema de competência técnica dos atuantes no setor cultural em nível municipal, ao sintetizar e esclarecer de forma concatenada e sequencial como organizar o sistema municipal de cultura. Tal Modelo Lógico pode contribuir também como um instrumento formativo para estimular a participação cidadã tanto no setor da cultura quanto em outros setores.

\section{Agradecimentos}

O presente trabalho foi realizado com apoio da Coordenação de Aperfeiçoamento de Pessoal de Nível Superior - Brasil (CAPES) - Código de Financiamento 001.

\section{Referências}

Bardin, L. (2016). Análise de conteúdo. São Paulo: edições 70.

Brasil (2012). Guia de Orientações para os Municípios - Sistema Nacional de Cultura: Perguntas e Respostas. Brasília: Ministério da Cultura.

Calabre, L. (2009). A coleta de informações e a construção de indicadores no campo da cultura: reconstituição do processo. Anais do Congresso Consad de Gestão Pública, Brasília, DF, Brasil, 2.

Cassiolato, M., \& Gueresi, S. (2010). Como elaborar modelo lógico: roteiro para formular programas e organizar avaliação. Nota Técnica. Brasília: IPEA.

Coelho, J. T. (1997). Dicionário crítico de política cultural: Cultura e imaginário. Dicionário crítico de política cultural: cultura e imaginário.

Coll-Serrano, V., Carrasco-Arroyo, S., Blasco-Blasco, O., \& Vila-Lladosa, L. (2012). Sistema de Indicadores Culturales Local (SICLO). El professional de la información, 21(1).

Coimbra, K. E. R., \& de Morais, M. D. C. (2019). Eleições presidenciais 2018 e gestão Bolsonaro: o não lugar da cultura. Argumentum, 11(3), 140-156.

Cunha Filho, F. H. (2010). Federalismo cultural e sistema nacional de cultura: contribuição ao debate. edições UFC.

Emenda Constitucional n.48, de 10 de agosto de 2005. (2005). Acrescenta o $§ 3^{\circ}$ ao art. 215 da Constituição Federal, instituindo o Plano Nacional de Cultura. Casa Civil: Brasília, em 10 de agosto de 2005. Recuperado de http://www.planalto.gov.br/ccivil 03/constituicao/Emendas/Emc/emc48.htm

Emenda Constitucional n.71, de 29 de novembro 2012. (2012). Acrescenta o art. 216-A à Constituição Federal para instituir o Sistema Nacional de Cultura. Casa Civil: Brasília, DF. Recuperado de http://www.planalto.gov.br/ccivil 03/Constituicao/Emendas/Emc/emc71.htm

Escande, S. (2003). Entre mito e realidade: quarenta anos de produção de indicadores culturais na França. Políticas Públicas Culturais para o Desenvolvimento: uma base de dados para a cultura. Brasília: UNESCO, pp.143-158.

Faguet, J. P. (2014) Decentralization and governance. World Development, 53, 2-13.

Ferres, K., Adair, D., \& Jones, R. (2010). Cultural indicators: Assessing the state of the arts in Australia. Cultural trends, 19(4), 261-272.

Gerbner, G. (1969). Toward "cultural indicators": The analysis of mass mediated public message systems. Educational Technology and Development, 17(2), 137-148.

Gonçalves, M. T., \& Simões, J. M. (2016). A articulação entre os conselhos de políticas culturais dos municípios da baixada fluminense e os elementos do Sistema Nacional de Cultura. Anais do Congresso Brasileiro de Estudos Organizacionais, Porto Alegre, RS, Brasil, 4.

Hong, B. (2014). National cultural indicators in New Zealand. Cultural Trends, 23(2), 93-108.

Jannuzzi, P. M. (2005). Indicadores para diagnóstico, monitoramento e avaliação de programas sociais 
no Brasil. Revista do Serviço Público, 56(2), 137-160.

Jannuzzi, P. M. (2014). Avaliação de programas sociais: conceitos e referenciais de quem a realiza. Estudos em Avaliação Educacional, 25(58), 22-42.

Johanson, K., Research Glow, H., \& Kershaw, A. (2014). New mode so farts participation and the limits of cultural indicators for local government. Poetics, 43, 43-59.

Lei n. 12.343, de 2 de dezembro de 2010. (2010). Institui o Plano Nacional de Cultura - PNC, cria o Sistema Nacional de Informações e Indicadores Culturais - SNIIC e dá outras providências. Casa Civil: Brasília. Recuperado de http://www.planalto.gov.br/ ccivil 03/ ato2007-2010/2010/lei/l12343.htm

Madden, C. (2005). Indicators for arts and cultural policy: a global perspective. Cultural Trends, 14(3), 217-247.

Mamede, W. (2020). Proposta de análise segundo a Teoria da Mudança: do Ciência Sem Fronteiras ao Programa Institucional de Internacionalização. Parcerias Estratégicas, 24(48), 133-150.

Martins, B. C. L., Vitória, J. R., Emmendoerfer, M. L., \& Fioravante, A. S. A. (2017). As Mudanças na Administração Pública e as Políticas Culturais no Brasil. Revista Interdisciplinar de Gestão Social, 5(3).

Moreira, V. S., \& Silveira, S. D. F. R. (2015). Indicadores de desempenho do Programa Minha Casa, Minha Vida: avaliação com base na satisfação dos beneficiários. Cadernos Gestão Pública e Cidadania, 20(66).

Morra-Imas, L. G., \& Rist, R. C. (2009). The road to results: Designing and conducting effective developmentev aluations. World Bank Publications.

Mozzato, A. R., \& Grzybovski, D. (2011). Análise de conteúdo como técnica de análise de dados qualitativos no campo da administração: potencial e desafios. Revista de Administração Contemporânea, 15(4), 731-747.

Musa, C. A.; Passador, C. S. ; Paschoalotto M. A. C. (2017) . Políticas públicas culturais no Brasil: um estudo de caso do Consórcio Intermunicipal Culturando. Anais do Encontro Brasileiro de Administração Pública, João Pessoa, PB, Brasil, 4.

Ortega-Villa, L. M., \& Ley-Garcia, J (2017). Analysis is of Cultural Indicators: A Comparison of Their Conceptual Basis and Dimensions. Social Indicators Research, 137(2), 413-439.

Pawson, R., \& Tilley, N. (2004). Realist evaluation. London: Sage.

Peixe, J. R. (2013). Sistemas de cultura. Salvador: Secretaria de Cultura do estado da Bahia.

Pires, R. R. C., Lopez, F. G., \& Silva, F. D. S. (2010). Métodos qualitativos de avaliação e suas contribuições para o aprimoramento de políticas públicas. In J. C. Cardoso Jr. (Coord.). Brasil em Desenvolvimento: Estado, planejamento e políticas públicas (pp. 661-688). Brasília: IPEA.

Portaria MinC n. 123, de 13 de dezembro de 2011. (2011). Estabelece as metas do Plano Nacional de Cultura - PNC. Diário Oficial da União, Brasília, publicado em 14 de dezembro de 2011.

Rubim, A. A. C. (2006). Políticas culturais no Brasil: tristes tradições. Galáxia. Revista do Programa de Pós-Graduação em Comunicação e Semiótica. ISSN 1982-2553, (13), 101-113.

Souza, E. C. L. (2002). A capacitação administrativa e a formação de gestores governamentais. Revista de Administração Pública, 36(1), 73-88.

Silva, P. L. (1999). Modelo de avaliação de programas sociais prioritários: relatório final. Programa de Apoio à Gestão Social no Brasil. Campinas, NEPP-UNICAMP.

Silva, F. B. D., \& Ziviani, P. (2020). O Incrementalismo pós-constitucional e o enigma da desconstrução: uma análise das políticas culturais. Texto para discussão 2550. Brasília; Rio de Janeiro: IPEA.

Sridharan, S., \& Nakaima, A. (2011). Ten steps to making evaluation matter. Evaluation and program planning, 34(2), 135-146.

Tabrett, L. (2014). The development of cultural indicators for Australia-policy-making in a federal system of government. Cultural Trends, 23(2), 82-92.

Vitória, J. R. (2015). Análise Institucional do Sistema Municipal de Cultura no Contexto Brasileiro. Dissertação de mestrado. Universidade Federal de Viçosa, Viçosa, MG, Brasil.

Vitória, J. R., \& Emmendoerfer, M. L. (2015). Dificuldades na implementação de um sistema municipal de cultura no Brasil a partir de práticas isomórficas. Políticas Culturais em Revista, 8(1), 222-238.

Vitória, J. R., Martins, B. C. L., Emmendoerfer, M. L., \& Fioravante, A. S. A. (2015). Estado, Políticas Públicas e os Desafios para a Descentralização: a Experiência da Secretaria de Estado de Cultura de Minas Gerais. Administração Pública e Gestão Social, 7(4), 206-217.

Weingast, B. R. (2014) Second generation fiscal federalism: political aspects of decentralization and economic development. World Development, 53, 14-25.

Weiss, C. H. (1999). The interface between evaluation and public policy. Evaluation, 5(4), 468-486. 
WK Kellogg Foundation. (2004). Logic Model Development Guide: Using Logic Models to Bring Together Planning, Evaluation and Action. W K Kellogg Foundation 